\title{
AS PROJEÇÕES ENUNCIATIVAS EM PRODUÇÕES TEXTUAIS DE ALUNOS DO ENSINO MÉDIO
}

\section{THE ENUNCIATIVE PROJECTIONS IN TEXTUAL PRODUCTIONS OF HIGH SCHOOL STUDENTS}

\author{
Marcia Andrade Morais ${ }^{1}$ \\ UFRJ - Universidade Federal do Rio de Janeiro
}

\begin{abstract}
RESUMO: Partindo das perspectivas dos estudos sobre texto e discurso, considera-se todo discurso uma confluência de vozes que torna, por sua vez, toda fala polifônica. Nesse ponto de vista, o presente trabalho tem como objetivo analisar os modos de instauração das categorias de pessoa em textos de alunos do Ensino Médio, produzidos predominantemente na tipologia argumentativa. Para tanto, a análise comportará dois aspectos no trato dos textos dos alunos: (i) os efeitos de sentido causados pela escolha de um narrador explícito ou implícito na projeção de primeiro grau e (ii) os recursos de inserção da voz do outro utilizados pelos alunos, por meio do discurso direto, e sua força argumentativa no texto. Dessa maneira, sob o sustentáculo da teoria semiótica de linha francesa, observar-se-á de que modo os recursos utilizados pelos alunos contribuem para uma significação do todo nos textos e em que medida tais recursos são eficientes ou não para o projeto argumentativo dos textos. Nesse sentido, a análise pretende realizar um recorte das estratégias de inserção da voz do outro no discurso, focalizando as projeções de pessoa, e também tecer uma avaliação crítica com relação aos efeitos de sentido causados pelo uso desses recursos.
\end{abstract}

PALAVRAS-CHAVE: Polifonia; projeções enunciativas; efeitos de sentido; produções textuais.

ABSTRACT: Using the perspectives of studies on text and speech, all speech is considered a confluence of voices that makes all speech polyphonic. From this perspective, this study aims to examine ways of establishing the categories of person in texts of high school students, produced predominantly in the argumentative type. To this end, the analysis must include two aspects in dealing with students' texts: (i) the effects of meaning caused by the choice of a narrator's explicit or implicit in the projection of the first degree and (ii) the resources for integrating the voice of the other used by students, through direct speech, and his force of argument in the text. Thus, under the mainstay of semiotic theory of the French line, will observe how the resources used by students to tribute a whole meaning of the texts and to what extent those remedies are effective or not for the project argumentative texts. In this sense, the analysis intends to implement an outline of strategies for entering the other's voice in speech, focusing on the projections of person. The analysis also intends to make a critical evaluation regarding the effects of meaning caused by the use of these resources.

KEYWORDS: Polyphony; enunciative projections; meaning effects; textual productions.

\footnotetext{
${ }^{1}$ Professora da rede pública e estudante da área de Letras no programa de Língua Portuguesa, com foco de pesquisa na área de semiótica. 


\section{Introdução}

O presente trabalho tem como objetivo investigar os modos de instauração das projeções enunciativas de pessoa em textos de alunos do Ensino Médio, considerando, também, os efeitos de sentido causados pela escolha de um narrador explícito ou implícito na projeção de primeiro grau e os recursos de inserção da voz do outro utilizado pelos alunos, por meio do discurso direto, e sua força argumentativa no texto.

Para tanto, parte-se da premissa, proposta pela teoria semiótica, de que a produção de sentido se faz por meio de um percurso gerativo do sentido, que parte de um nível mais abstrato para um mais concreto, haja vista as etapas percorridas até a produção de significação dos textos - nível das oposições fundamentais, nível narrativo e nível discursivo. Para esta análise, então, o foco será no último nível, o discursivo, uma vez que é nele que se podem observar as projeções enunciativas.

O nível discursivo compreende, assim como os demais, uma sintaxe e uma semântica que orientam o caminho de análise dos textos. Para este estudo, considerar-se-á somente a sintaxe discursiva, que abarca as projeções da enunciação no enunciado e as relações entre enunciador e enunciatário.

Assim, serão sustentáculos fundamentais de análise os estudos de José Luiz Fiorin sobre as projeções enunciativas, sobretudo a obra As astúcias da enunciação (1996), em que o autor esmiúça a questão das projeções, bem como os mecanismos em que se projetam no enunciado as instâncias de tempo, pessoa e espaço. Cumpre destacar que, para esta pesquisa, considerar-se-á, somente, a projeção de pessoa no enunciado.

O objeto de análise é composto de duas redações de alunos do Ensino Médio, nas quais há predominância de tipologia argumentativa, ambas escritas a partir do tema: "Impunidade na sociedade brasileira: o que fazer para superar essa tradição cultural negativa?", aplicado pelo curso pré-vestibular do CEDERJ.

Dessa forma, os objetivos desta análise giram em torno da verificação da instauração de vozes pelos alunos nos textos, além da observação da eficácia ou não dos recursos utilizados para o direcionamento argumentativo e para a construção de uma intencionalidade nos textos.

\section{As projeções de pessoa}

Antes da exposição dos fundamentos teóricos específicos utilizados para esta análise, cumpre ressaltar as noções de enunciação e enunciado. Para Benveniste (1976, p.222), a situação da enunciação é única e, portanto, irrecuperável. Entretanto é possível, por meio das "pistas" deixadas pelo enunciador no texto, analisar o enunciado, produto da enunciação, a fim de pressupor os elementos do momento da produção do discurso.

Nesse sentido, é importante ressaltar também que, ao se criar o discurso, inscreve-se um enunciatário, categoria que constitui o sujeito da enunciação, participante da produção do enunciado como imagem inscrita no texto, interferindo nas escolhas enunciativas. Nas produções analisadas, esse será um aspecto de análise fundamental para entender as escolhas do enunciador em seu texto.

Além disso, o autor considera também ser o diálogo a condição constitutiva da pessoa, tendo em vista que o eu existe em oposição ao tu, construído na reversibilidade dos papéis entre as duas pessoas. É importante esclarecer que, quando se fala nas instâncias enunciativas no discurso, trata-se de um aspecto linguístico, ou seja, não se refere a seres de 
carne e osso, mas a um autor implícito no texto, tendo em vista que é a obra o objeto de estudo e, portanto, é esse autor implícito pertencente ao estudo da enunciação.

De acordo com os pressupostos teóricos apresentados, o ponto de referência no que diz respeito às categorias de pessoa, tempo e espaço no discurso é o sujeito da enunciação, ou seja, é o responsável pela produção do enunciado. A enunciação, por sua vez, pressupõe a instauração de um sujeito enunciador que, consequentemente, inscreve no discurso um enunciatário. Nesse contexto, o enunciatário não é somente destinatário da mensagem produzida, mas também contribui para a produção de sentido na medida em que "todo enunciado é construído levando em conta uma imagem do enunciatário; sem isso, o discurso não teria eficácia, pois não atingiria ou não seria aceito por seu destinatário." (GOMES, 2008, p. 3)

A enunciação se subdivide em três níveis, de acordo com as instâncias enunciativas que se instalam no texto. O primeiro nível compreende os actantes da enunciação, o enunciador e o enunciatário, o primeiro fazendo as vezes do destinador e o segundo, do destinatário, ambos implícitos.

No segundo nível da enunciação, estão as instâncias de destinador e destinatário instalados no enunciado, que correspondem aos actantes da enunciação enunciada, o narrador e o narratário. O narrador cumpre a função de assumir a voz do que é anunciado no texto, o que não significa dizer que, necessariamente, o narrador apareça através de um eu explícito, o mesmo pode estar implícito, instituindo a impressão de que os fatos se desenrolam por si mesmos e que são apresentados com um caráter de realidade, verdade (FIORIN, 2009, p.56).

O narrador é o actante da enunciação responsável pelo saber pragmático, considerando que é dele a responsabilidade de organizar as estruturas narrativas, ou seja, relatar a história como um todo, assumindo determinadas funções na narrativa, como a função ideológica, o direcionamento, a atestação da veracidade dos fatos e a comunicação. Nesse sentido, de acordo com Fiorin (1996, p.107), as funções do "falar" e do "relatar" cabem ao narrador, enquanto o papel de saber sobre os fatos compete ao observador, instância responsável pelo saber cognitivo.

É importante, neste momento, contrapor os diferentes conceitos a respeito da instância do narrador no discurso. Para Barros (1988, p. 81), explicita-se a figura do narrador apenas nas narrativas em primeira pessoa, ou seja, quando quem toma a palavra no discurso diz eu, cabendo à figura do observador os casos de narrativa em terceira pessoa.

Já para Fiorin (1996, p. 104), toda narrativa pressupõe um narrador uma vez que, como já foi dito anteriormente, a ele cabe a dimensão pragmática na enunciação. Assim, inclusive nas narrativas de terceira pessoa, há a instância do narrador, tendo em vista que, nesse contexto, as narrativas em terceira pessoa seriam não aquelas em que o narrador diz ou não eu, mas aquelas em que o narrador não participa dos fatos narrados, até mesmo pelo fato de que, segundo o autor, "toda narração é virtualmente feita em primeira pessoa". (idem)

Ao narrador, então, corresponde todo o direcionamento da narrativa, pois é ele quem conduz os fatos narrados, relatando o que o observador sabe. Entende-se, então, que as funções de observador e narrador são distintas, podendo, todavia, haver um sincretismo entre os dois actantes.

No que diz respeito aos textos predominantemente argumentativos, no caso as produções textuais dos alunos, é possível afirmar que o narrador controla as projeções instauradas no texto, tendo em vista o objetivo final da argumentação: fazer o enunciatário crer no ponto de vista defendido no discurso. 
Por esse motivo, os actantes que por ventura se inscrevam no discurso provavelmente terão seus pontos de vista direcionados ao projeto argumentativo do texto - o narrador pode instaurar uma voz com a qual não concorda para depois apresentar outros argumentos contrários que fortaleçam seu ponto de vista, como pode encenar no discurso um consenso ao inserir no texto outras vozes que corroboram o seu ponto de vista.

Assim, é possível perceber que, dentre os textos que se propõem a defender determinado ponto de vista, ainda que o foco se alterne através da inserção de diferentes actantes, o objetivo é que, na leitura global do texto, seja percebida a voz soberana do narrador, tendo em vista que é o ponto de vista do narrador que deve prevalecer para que a produção de sentido do texto seja coerente com o projeto argumentativo e, consequentemente, o texto seja aceito pelo enunciatário.

Portanto, o narrador, ao dar a voz a um actante do enunciado, constitui as instâncias de interlocutor e interlocutário, pressupondo uma situação de diálogo. Segue um quadro representativo dos níveis de enunciação, adaptado de Barros (1988, p. 57):

\begin{tabular}{|c|c|c|}
\hline $\begin{array}{c}\text { INSTÂNCIAS } \\
\text { PRESSUPOSTAS }\end{array}$ & ENUNCIADOR & ENUNCIATÁRIO \\
\hline $\mathbf{1}^{\mathbf{0}}$ GRAU & NARRADOR & NARRATÁRIO \\
\hline $\mathbf{2}^{\mathbf{0}}$ GRAU & INTERLOCUTOR & INTERLOCUTÁRIO \\
\hline
\end{tabular}

A essa instauração das pessoas no discurso correspondem, então, os mecanismos de debreagem e embreagem actanciais. A debreagem indica a separação da instância da enunciação, projetando para fora de si elementos ligados a sua estrutura original, no caso estudado, a pessoa. Já a embreagem incorre na operação oposta, de efeito de retorno à enunciação a partir da neutralização da categoria de pessoa.

No caso em questão, a discussão centrar-se-á somente na debreagem enunciativa e enunciva - uma vez que são estes os procedimentos utilizados pelos alunos nas produções textuais analisadas. O objetivo, então, será examinar, a partir da leitura global dos textos, os efeitos de sentido causados pela escolha de determinado tipo de projeção, ou seja, se de fato contribui para o projeto argumentativo dos textos dos alunos.

Cumpre apontar que, de acordo com Fiorin (1996), há dois tipos de debreagem actancial - a enunciativa e a enunciva. Naquela, instalam-se no enunciado os actantes da enunciação (eu/tu), enquanto nesta instaura-se o actante (ele). Assim, no que diz respeito ao mecanismo de debreagem, observar-se-ão como as escolhas pelos dois diferentes tipos de debreagem - enunciva ou enunciativa - influenciam no sentido dos textos dos alunos.

Nesse sentido, será verificado, também, a partir da produção textual selecionada, de que modo o mecanismo de debreagem interna - a instauração da voz do outro através de uma projeção de segundo grau - produz os sentidos desejados pelo enunciador no direcionamento argumentativo do texto e no objetivo de tentar convencer o enunciatário sobre seu ponto de vista.

\section{Um caminho de análise dos textos}

Os textos analisados fazem parte do banco de redações do curso pré-vestibular do CEDERJ, produzidas em uma situação de simulado, com o intuito de preparar os alunos para a situação de produção de texto para os grandes vestibulares. A partir do tema geral "a questão da impunidade no Brasil", foram apresentados aos alunos quatro textos de apoio que tinham relação com o tema, pois apresentavam casos de morosidade na aplicação das leis na 
nossa sociedade, e a exigência era a de que os alunos dissertassem sobre o tema "Impunidade na sociedade brasileira: o que fazer para superar essa tradição cultural negativa?".

São dois textos selecionados para esta análise, sendo cada um usado para um tipo de análise diferente. Na análise da questão do narrador, está o TEXTO I, cujo título é "Impunidade: motivação para os criminosos", e no aspecto das projeções de $2^{\circ}$ grau no discurso está o TEXTO II com o título "Impunidade: essa tradição negativa".

\section{A projeção de $1^{\circ}$ grau - o narrador}

No âmbito das projeções enunciativas, encontra-se a projeção de $1^{\circ}$ grau referente às instâncias do narrador e do narratário, que são os sujeitos diretamente delegados do enunciador e enunciatário. Segundo Fiorin, "mesmo que não haja um eu explicitamente instalado por uma debreagem actancial enunciativa, há uma instância do enunciado que é responsável pelo conjunto de avaliações e, portanto, um eu" (1996, p.67).

Assim, em todo texto, narrativo ou não, há sempre a instância de um narrador no enunciado, uma vez que ele é o responsável pela organização do texto, através de elementos como marcação temporal e espacial, direcionamento e função ideológica do texto, dentre outros. E, desse modo, compreende-se que há dois tipos de narradores: o explícito e o implícito. Ao dizer eu / tu, o narrador constrói-se explicitamente, ao passo que quando não o faz, deixa implícita sua inscrição.

Os textos analisados correspondem a uma produção textual de tipologia predominantemente argumentativa, como dissemos. Na produção analisada, o TEXTO I, de título "Impunidade: motivação para os criminosos", o ponto de vista defendido é o de que há muitos casos de pessoas que cometem crimes e não são punidas pelos seus atos, o que, de acordo com o narrador, estimularia outras pessoas a praticarem crimes, tendo em vista que a ideia que circula em nosso país é que há uma morosidade no cumprimento das leis e na punição de pessoas que cometem atos ilícitos.

De início, é importante ressaltar que, ao instalar no discurso um eu e encenar a enunciação no interior do enunciado - debreagem enunciativa -, o narrador cria um certo efeito de subjetividade, ao passo que, ao optar pela retirada das marcas da enunciação no enunciado - debreagem enunciva -, cria-se um efeito de objetividade. De acordo com Fiorin:

As debreagens enunciativa e enunciva produzem dois tipos básicos de discurso: os de primeira e os de terceira pessoa. Essas duas espécies de debreagens produzem, respectivamente, efeitos de sentido de subjetividade e de objetividade, porque, na debreagem enunciativa, o eu coloca-se no interior do discurso, enquanto na enunciva, ausenta-se dele. [...]. Assim, narrar em primeira ou terceira pessoa é uma opção feita pelo enunciador, visando transmitir efeitos de subjetividade ou objetividade. (Fiorin, 2008, p. 64)

A partir da leitura global do texto, é possível perceber que o procedimento predominante de projeção de pessoa é a debreagem enunciva, tendo em vista as diversas passagens elencadas a seguir, retiradas do texto I:

O Brasil é um país onde existe muita violência. Contudo na maioria das vezes quem comete os atos de vandalismo ficam impunes [sic], o que dá motivação aos criminosos para continuarem os cometendo. A justiça brasileira deveria tomar uma atitude rígida para pôr um fim a essa barbárie. 
Acontecem crimes absurdos que chocam a população, mas até nos dias atuais, nenhuma medida drástica foi tomada. [...]

Um exemplo de impunidade foi o escândalo do mensalão que ocorreu na política brasileira. [...]

O primeiro passo para acabar com esses tos egoístas seria que os criminosos cumprissem suas penas completas por menores que fosse [sic], que houvesse um respeito as autoridades. [...]

Ninguém teria o direito de pagar pelo crime que cometeu. [...]

A escolha predominante, no texto, é pelo mecanismo de debreagem actancial enunciva, tendo em vista que a maior parte do texto é escrita em terceira pessoa do singular/plural, como ilustram os vários exemplos expostos anteriormente. Ou seja, ao se considerar o propósito geral do texto, de acordo com elementos linguísticos predominantes, verifica-se um efeito de sentido de afastamento do enunciador em relação ao conteúdo enunciado.

No decorrer de sua argumentação, o narrador inscreve-se pontualmente de maneira explícita quando se apresenta por meio de um eu que busca expor a sua perspectiva em relação ao tema desenvolvido no texto. Segue o trecho, situado no meio do segundo parágrafo:

Penso que, com os atos de violência que vem acontecendo ao longo dos anos, sem nenhuma punição, as pessoas acabam se acostumando a ouvir notícias de morte, sequestros e roubos no seu dia a dia, e se esse 'mal' não for cortado pela raiz, poderá ter um fim bem pior do que está. [...]

Acredito que, seguindo este caminho, teremos um país melhor e até seres humanos melhores.

Nota-se que, nesse excerto, há a opção pelo mecanismo de debreagem actancial enunciativa, uma vez há uma projeção do ato de enunciar - "penso" e "acredito" no interior do enunciado. O narrador, nesses trechos, faz a opção pela inscrição da marca da enunciação no enunciado, pelo uso do verbo "pensar" e "acreditar" na primeira pessoa, que simula a presença do enunciador no enunciado e faz referência à instância da enunciação no discurso, produzindo determinados efeitos de sentido ao texto.

Todavia é importante analisar as circunstâncias da inscrição da primeira pessoa do singular no texto. No contexto da projeção, é possível notar determinada amenização do conteúdo pessoal, ou seja, a força do saber sobre os conteúdos é amenizada, alterando o engajamento epistêmico do narrador em relação ao seu dizer. Diferentemente das outras inscrições em que o conteúdo veiculado é considerado como algo indiscutível e irrefutável, a projeção explícita do narrador no discurso, nos contextos analisados, aproxima-se claramente a um discurso bem pessoal do enunciador através de uma carga subjetiva forte particularizadora - é questionável o fato de as pessoas se acostumarem a ouvir notícias de morte sem nenhuma punição, mas é indiscutível que o mensalão ficou bastante conhecido em nossa sociedade como um caso típico de impunidade, por exemplo.

Assim, pode-se perceber que, ao utilizar a primeira pessoa do singular, cria-se, com o efeito de subjetividade, um sentido de aproximação do enunciador em relação ao 
enunciatário, ao passo que o uso da terceira pessoa, como, por exemplo, no trecho "a justiça brasileira deveria tomar", produz o efeito contrário: o de afastamento e o de verdade, modalizando o enunciado por um saber ser e um dever ser.

Nesse contexto, entende-se que não há uma coerência no que diz respeito ao tipo de projeção enunciativa instaurada no texto, uma vez que a escolha pelo mecanismo de debreagem actancial enunciativa denota certo efeito de proximidade com a situação de enunciação, em virtude da inscrição de um eu de maneira explícita no enunciado, ao passo que a opção pelo uso de debreagem actancial enunciva remete a uma ideia de afastamento do simulacro do ato de enunciar, com o uso da terceira pessoa.

$\mathrm{Na}$ leitura do texto de maneira geral, observa-se que tais escolhas causam um efeito de sentido contraditório à orientação argumentativa do texto. A inscrição de um narrador explícito permite a leitura de que o enunciador pretende defender que é aquele o seu ponto de vista pessoal, pertencente à voz do narrador no discurso, diferente das outras vozes que se inscrevem em seu texto, não correspondendo necessariamente a uma realidade. Todavia, mesmo na opção pelo discurso em terceira pessoa, o enunciado deixa pressuposto o enunciador responsável pelo enunciado, ou seja, não é necessário haver um eu explícito para que haja um responsável pelo dito.

$\mathrm{Na}$ produção analisada, conforme já foi dito anteriormente, a escolha predominante é pela projeção enunciva de pessoa, tendo em vista que o texto é escrito majoritariamente em terceira pessoa, o que cria o sentido de que os argumentos apresentados são fatos aparentemente indiscutíveis, uma vez que dá um caráter de objetividade ao texto, com ideias plenamente aceitas pelo senso comum e, portanto, consideradas incontestáveis. Esse recurso de objetividade contribui para a argumentação do texto, na medida em que quanto mais intensa é a certeza do narrador quanto às ideias apresentadas, mais facilmente o enunciatário vai aderir ao ponto de vista defendido pelo enunciador.

Entretanto, quando se faz a opção pela projeção enunciativa de pessoa, o efeito de sentido criado é o de subjetividade, e, no texto, não há um objetivo claro que a justifique, já que, no contexto do uso da projeção enunciativa, nota-se que se trata de argumentos de cunho pessoal particularizantes, discutíveis, refutáveis.

Neste ponto, é necessário considerar o gênero textual em questão, a dissertação escolar. Nem sempre o uso de primeira pessoa gera um efeito de sentido negativo nos textos opinativos, relacionando o gênero à questão da objetividade e subjetividade. Em determinados contextos, em artigos de opinião, a aproximação do enunciador ao enunciatário e a pessoalização do conteúdo enunciado são não só propositais, como também muito eficazes, já que conseguem o envolvimento do enunciatário.

No caso da produção analisada, nota-se que não há uma uniformidade no que diz respeito ao tipo de projeção enunciativa instaurada no texto, uma vez que a escolha pelo mecanismo de debreagem actancial enunciativa denota certo efeito de proximidade com a situação de enunciação, em virtude da inscrição de um eu de maneira explícita no enunciado, ao passo que a opção pelo uso pela debreagem actancial enunciva remete a uma ideia de afastamento do simulacro do ato de enunciar com o uso da terceira pessoa.

$\mathrm{Na}$ leitura do texto selecionado, de maneira geral, observa-se que tais escolhas nem sempre causam um efeito de sentido coerente com o projeto argumentativo no texto. A inscrição de um narrador explícito permite a leitura de que o enunciador pretende defender que é aquele o seu ponto de vista pessoal, pertencente apenas à voz do narrador no texto, diferentemente das outras vozes que se inscrevem em seu texto, não correspondendo necessariamente a uma realidade. Todavia, mesmo na opção pelo texto em terceira pessoa, o 
enunciado deixa pressuposto o enunciador responsável pelo seu dizer, ou seja, não é necessário haver um eu explícito para que haja um responsável pelo dito.

Relacionando a discussão das projeções ao ensino, é possível perceber que, em muitos livros didáticos ou nas orientações de cursos pré-vestibulares, não há explicações plausíveis sobre a eficiência ou não das estratégias de projeção de pessoa em determinados contextos, o que explica a falta de habilidade dos discentes em utilizar de maneira proficiente os recursos de debreagem enunciativa e também a falta de orientação para os docentes explorarem as questões relativas às projeções actanciais em sala de aula. Ou seja, há regras que determinam o que pode ou não ser feito na produção do texto, mas não há, na maioria das vezes, a explicitação do motivo, quiçá a explanação dos efeitos de sentido imbricados na escolha de uso de determinado tipo de debreagem.

Isso pode ser corroborado com a intervenção feita pelo avaliador dessa produção analisada, ao sugerir, em sua correção: "Não devemos utilizar a primeira pessoa do singular em dissertações".

Ora, somente dizer o que pode ou não ser feito em um determinado tipo de texto não é suficiente para levar o aluno a uma reflexão acerca da opção de uma escolha por outra. Nesse contexto, não há nada que leve o aluno a perceber os efeitos de sentido causados pelo uso da debreagem enunciativa/enunciva, tampouco uma compreensão sobre os recursos mais eficazes para a argumentação do texto, considerando a produção analisada de tipologia predominante argumentativa.

\section{A projeção de $2^{\circ}$ grau - o interlocutor}

Diferentemente de textos com predominância de tipologia narrativa, por exemplo, em que é recorrente a inserção do discurso direto, os textos opinativos de tipologia argumentativa predominante parecem apresentar a voz do outro, preferencialmente:

qualquer texto;

i. de maneira não mostrada e não demarcada - princípio inerente a

ii. de maneira mostrada e demarcada - através das aspas, no fio do discurso do narrador ou através do discurso indireto.

A produção textual em questão apresenta o discurso direto como recurso de inserção da voz do outro no texto. De acordo com Savioli e Fiorin (2006, p.44), o discurso direto é o "modo de citação do discurso alheio em que o narrador indica o discurso do outro e, depois, reproduz literalmente a fala dele".

Assim, o discurso direto é, por si, a consequência de uma debreagem interna e tem como marcas um verbo de dizer, a separação nítida entre a fala do personagem e a do narrador (por meio de aspas ou dois-pontos e travessão), bem como elementos espaçotemporais (pronomes, advérbios, verbos e outros) referentes ao narrador ou ao interlocutor, próprios de um eu e um tu recuperados linguisticamente pelas referências dêiticas.

O discurso direto tem a propriedade de criar um simulacro da enunciação, recurso que produz o sentido de que o narrador repete precisamente as palavras do interlocutor, dando ao texto um efeito de realidade, verdade.

A produção textual selecionada, conforme já foi mencionado anteriormente, desenvolve o tema da impunidade no Brasil, em que há a defesa do ponto de vista de que a lei 
não funciona para todos, e os únicos que são punidos são pessoas de classe menos favorecida economicamente; em contrapartida, os detentores do "poder" saem ilesos de seus crimes.

De acordo com o enunciador, isso acontece porque já está disseminada, em nossa sociedade, a ideia de que levar vantagem em tudo é uma manifestação de esperteza, considerando que é possível burlar as leis, sem esperar nenhum castigo por tal atitude. Nesse momento, o enunciador insere um trecho de discurso direto, a princípio pertencente à fala de um jogador de futebol famoso, veiculada em uma propaganda televisiva de bastante repercussão na época. Eis o trecho: "Há alguns anos, o jogador de futebol Gérson usou uma frase em um comercial de televisão que virou o 'modus operandi' de muitos: 'gosto de levar vantagem em tudo, certo?"'.

No trecho em destaque, é possível notar a inserção do discurso direto por meio de elementos como a separação entre a fala do narrador e a do actante da enunciação, por intermédio dos usos das aspas e dos dois-pontos, a indicação do uso da frase dita pelo jogador, fato anunciado pela marcação temporal - "há alguns anos" - e espacial - "em um comercial de televisão".

Além dos recursos mencionados, através do discurso direto, utiliza-se o mecanismo de debreagem enunciativa interna. É enunciativa, uma vez que há um eu que se projeta no discurso, diferente do eu do narrador, e interna, tendo em vista que o narrador dá a palavra a um dos actantes já instalados no enunciado - o jogador Gérson - que se torna um enunciador em segundo grau e diferencia-se, portanto, da voz do narrador, projeção da enunciação em primeiro grau.

Interessante observar, então, nesse ponto, os efeitos de sentido causados pelo uso do mecanismo de uma projeção de pessoa de segundo grau na produção analisada. Primeiramente, cumpre destacar que a inserção do discurso direto tem por finalidade criar um simulacro da verdade, tendo em vista que se simula a inserção do discurso do outro tal qual aconteceu no momento da enunciação.

A impressão que se tem, então, é de preservação da integridade do discurso citado, em que o outro teria "falado com suas próprias palavras", reproduzindo literalmente a fala do outro. Entretanto trata-se de um simulacro à medida que, ainda que se procure criar o efeito de realidade, é impossível, somente através do discurso citado pelo narrador, ter a certeza da realidade do discurso.

Além disso, um efeito criado através da inserção da fala do outro é o de uma tentativa de fuga de um discurso de cunho autoritário, uma vez que, ao se simular a fala do outro, há uma aparente ideia de que se abre espaço para a inserção de outras vozes/opiniões diferentes da pertencente ao narrador, construindo, então, o efeito de um espaço democrático no qual se insere a voz do outro tal qual ela foi produzida, sem a intervenção do narrador.

Porém, é impossível negar que, ao inserir a voz do outro, ainda que por intermédio do discurso direto, há um controle do narrador sobre as projeções das vozes. Notese que a orientação argumentativa do texto gira em torno de quão disseminada já está na sociedade a ideia de que as pessoas gostam de levar vantagem em tudo e que muitos se consideram "espertos" por se comportarem dessa maneira.

Nesse sentido, a inserção do discurso do jogador Gérson só faz corroborar o ponto de vista defendido pelo narrador, já que, de acordo com o trecho citado, um jogador famoso - bastante conhecido na mídia - assume, em uma propaganda televisiva - portanto de grande veiculação na sociedade -, que gosta de levar vantagem em tudo.

$\mathrm{Na}$ produção analisada, há uma opção majoritária pelo mecanismo de debreagem enunciva de pessoa, constituindo-se o ele a projeção predominante em todo o texto. Todavia, no desenrolar da argumentação, opta-se por uma debreagem interna, a fim de 
inserir uma citação em discurso direto que corrobora o ponto de vista defendido pelo enunciador.

Esse recurso utilizado pelo enunciador, de fato, contribui para a argumentação do texto na medida em que ilustra, através de um exemplo emblemático, o ponto de vista defendido pelo enunciador: a cultura da impunidade está tão disseminada na nossa sociedade, chegando ao ponto de ser pauta de um comercial de televisão estrelado por um jogador de futebol.

Cabe ressaltar, por fim, que a estratégia utilizada pelo enunciador do texto cumpre o objetivo desejado, já que, através de uma aparente liberdade de manifestação de outras vozes no discurso, o narrador controla esta outra voz, fazendo com que a estratégia colabore com o projeto argumentativo pretendido, ao comentar negativamente o conteúdo da voz discordante.

\section{Considerações finais}

A partir das considerações da teoria semiótica a respeito do texto e dos recursos utilizados para a construção de sentido dos mesmos, foi possível perceber, no âmbito da sintaxe discursiva, os modos de projeções de pessoa nos textos de alunos de pré-vestibular que desejam ingressar em uma faculdade pública, submetendo-se, portanto, aos certames das grandes universidades.

Nesse sentido, pesquisou-se o modo de ocorrência dessas projeções sob o olhar das projeções de $1^{\circ}$ grau - o narrador e o narratário - e de $2^{\circ}$ grau - interlocutor e interlocutário. $\mathrm{O}$ estudo focalizou a questão da projeção de $1^{\circ}$ grau nos modos de instauração do narrador de maneira implícita ou explícita no texto, observando os efeitos de sentido decorrentes da escolha do tipo de debreagem utilizada - enunciativa ou enunciva.

Concernente à questão da projeção de segundo grau, a pesquisa verificou o modo de inserção da voz do outro através do discurso direto, preocupando-se, também, com os sentidos imbricados em determinado uso, bem como a eficácia ou não para a argumentação do texto.

O que se pode concluir da análise dos textos dos alunos, então, é que, em primeiro lugar, a preocupação do ensino, de maneira geral, gira em torno de um enquadramento da produção dos alunos em determinado modelo de texto, como se existisse uma "fórmula" que correspondesse a um texto padrão, escrito de maneira suficiente a fazer com que o aluno atinja o objetivo com aquele texto - conseguir uma boa nota e, portanto, uma boa colocação nos exames de vestibular.

Nesse modelo, não há espaço para uma reflexão a respeito das estratégias argumentativas usadas pelos alunos de modo a tornar o texto mais criativo, fazendo com que, muitas vezes, o aluno incorra no erro de não atingir os objetivos de maneira satisfatória com o uso de determinado recurso, uma vez que o discente não compreende o porquê de certa estratégia não ser eficaz, somente decora regras que são proibidas em alguns tipos de texto.

Além disso, seria de extrema importância inserir em sala de aula o debate sobre as projeções enunciativas no texto. Não significa dizer que esse tópico não esteja presente em sala de aula, mas, muitas vezes, o ensino limita-se a discorrer sobre o aspecto formal das projeções, desprezando os efeitos de sentido ocasionados por determinado uso.

Assim, compreender o grau de hierarquia das delegações de vozes, o controle do narrador sobre o dito, o poder instalado no texto através do uso do discurso de outrem, as variadas maneiras de inserir no texto outras vozes de modo a contribuir com a intencionalidade do texto é construir habilidades de leitura e produção de maneira proficiente, 
fazendo que o aluno empregue, de maneira autônoma, recursos que possibilitem uma maior competência discursiva nos diversos gêneros e tipologias textuais.

\section{REFERÊNCIAS}

BARROS, D. L. P. de. Teoria do discurso: fundamentos semióticos. São Paulo: Atual, 1988.

BENVENISTE, E. O aparelho formal da enunciação. In: Problemas de Linguística Geral I. Tradução de Maria da Glória Novak e Maria Luisa Neri. Campinas: Pontes Editores, 2005.

FIORIN, J. L. As astúcias da enunciação: as categorias de pessoa, espaço e tempo. São Paulo: Ática, 1996.

Elementos de análise do discurso. São Paulo: Contexto, 2009.

FIORIN, J. L. \& SAVIOLI, F. P. Lições de texto - leitura e redação. 5aed. São Paulo: Ática, 2006.

GOMES, R. S. Semântica e texto: polifonia e produção de sentido nas atividades de leitura. In: ANAIS DA II SEMANA DE LÍNGUA PORTUGUESA. Rio de Janeiro: UFRJ, 2008. 
CASA, Vol.10 n.1, julho de 2012

\section{Anexos}

TEXTO I

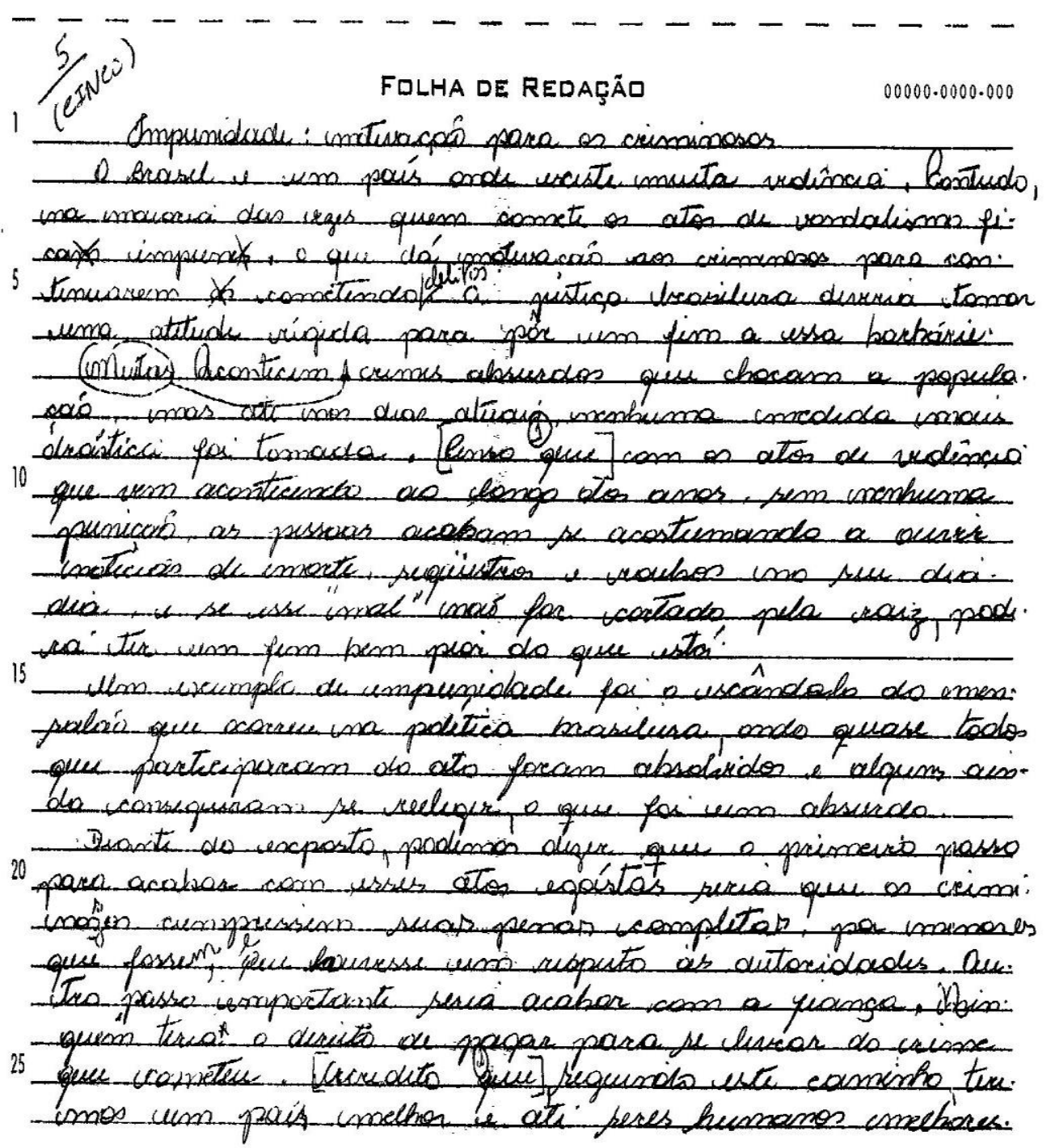

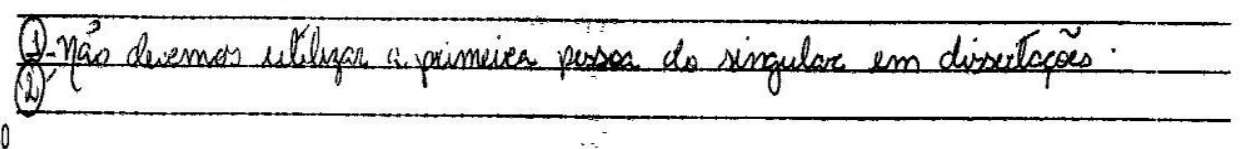

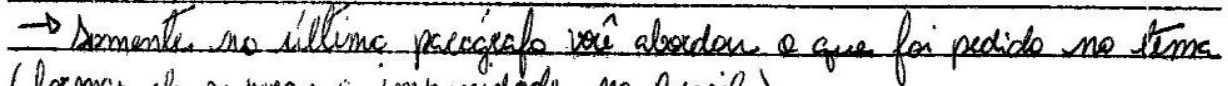

(formas ele supueac is impunidede no Beasil).

35

\begin{tabular}{|c|c|c|c|c|c|}
\hline (B) (B) (D) & (1) (1) (1) & $\begin{array}{l}2 \cdot \operatorname{Temo} / \text { Texto } \\
-(3) \text { (3) (4) }\end{array}$ & $\begin{array}{l}\text { 3. Sol. / OIg de deryurentios } \\
\text { (2) (3) (4) }\end{array}$ & 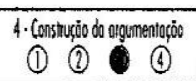 & 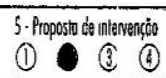 \\
\hline
\end{tabular}


TEXTO II

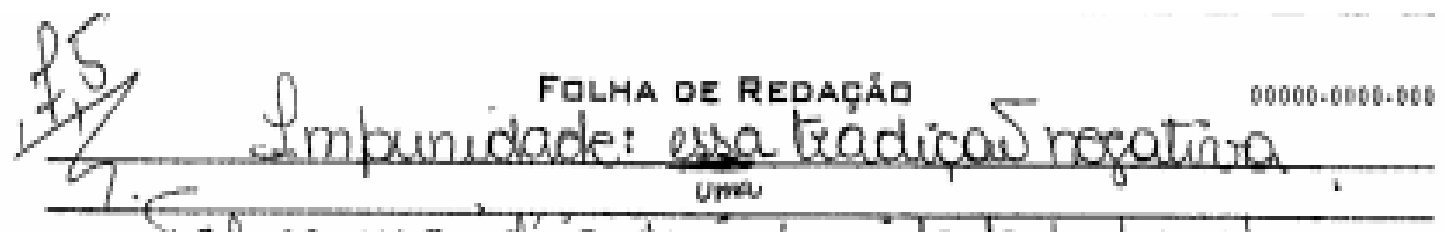

talner, essa id ia de impunidade tenha obexco com os chatuada coucules; os dones de lagendas, que

comoseu podir tranibulavam vidas destinos.

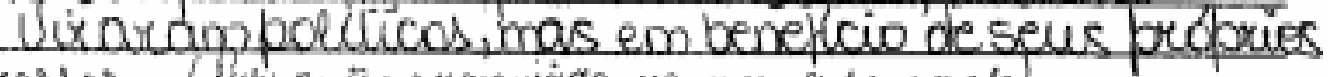

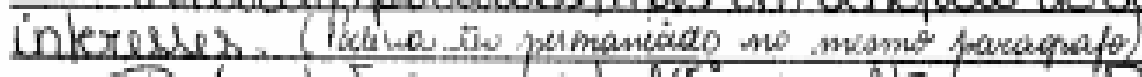

Dhí supoé se que pollicos, allo everultud, glandes empresories e culros podverosos estavecina do

10 berne db mais.

Estace cutras ercemples de bodex, aulotiatismo. amarincia duver co sido tradugidospela idicia de sucesso e epsecliza.

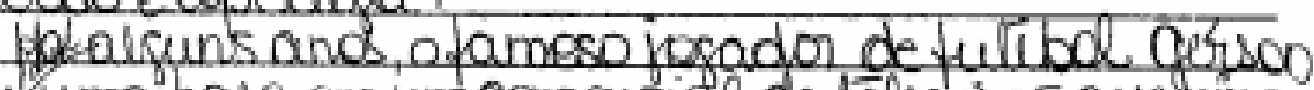

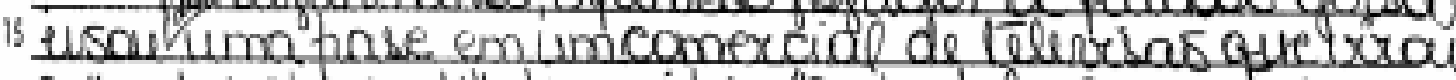
0 "modus gaecandi" de muilos: "Gosto de levar rontagemen tudo, cixto?

Entós baduru-se que a lantarem, mesmo que

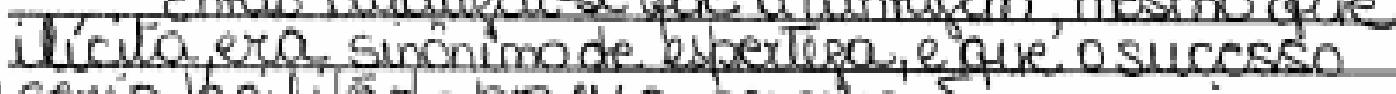

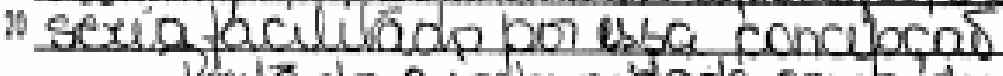
Parlantro impunidade cemb dine ser combatida eramenta para dizunar ese faciliádor de compo. lamentos ilcilol, para nos falar em crumes entro cidades.

25 Estó cahora de mudax estoc nosea luadicas

alraves de punices eremplaties e recstuuturacos

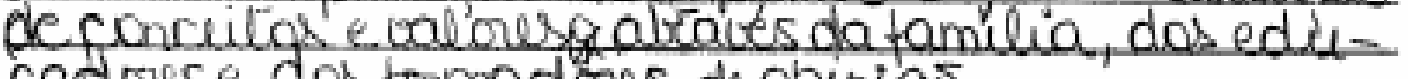
cadorere dos trmadros de opinias

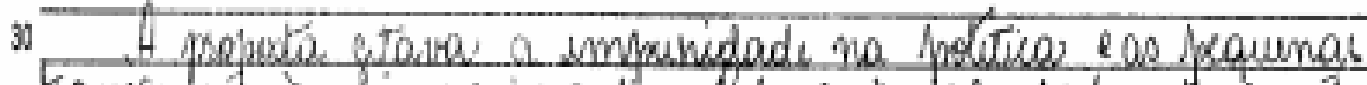

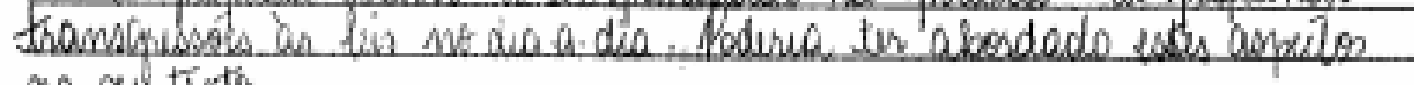
ins oultidi

s

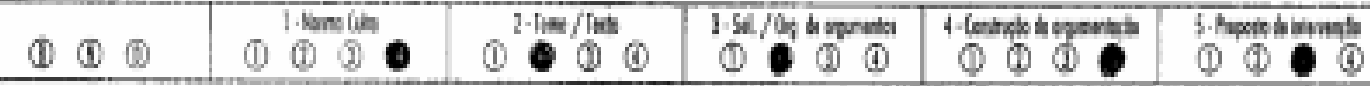

